\title{
Entre la forgerie y el pastiche: la obra tributo a Tintín de Yves Rodier
}

\section{Between forgerie and pastiche: Yves Rodier's tribute to Tintin works}

\author{
Dr. Miguel Ángel Pérez-Gómez \\ Departamento de Comunicación Audiovisual \\ y Publicidad de la Universidad de Sevilla
}

Miguel Ángel Pérez-Gómez es licenciado en Comunicación Audiovisual por la Universidad de Sevilla; en la actualidad es doctor y profesor del Departamento de Comunicación de la Universidad de Sevilla. Su tesis versa sobre la producción audiovisual del fandom y la cultura participativa. Entre otros eventos internacionales ha participado en Queer Screen Cultures (University of Nottingham, 2009), las AATI Conferences (Italia, 2010 y 2011) y Biografía del cómic (Universitá Ca’Foscari Venezia, 2014). Ha participado en libros como Los héroes están muertos (Dolmen, 2014), Fan Phenomena: The Lord of the Rings (Intellect, 2015) o Marvel Comics into Film (McFarland, 2016). Es también el editor del e-book Previously On: Multidisciplinary Studies on TV Series in the Third Golden Age of Television (2011). En sus ratos libres escribe sobre comics en su blog El lector bicéfalo, colaboró ocasionalmente en Rockdelux, y participó en la ya extinta Entrecomics.

Fecha de recepción: 2 de septiembre de 2020

Fecha de aceptación definitiva: 31 de octubre de 2020 


\title{
Resumen
}

Entre los apócrifos de Las aventuras de Tintín existen aquellos que, por imitación del estilo gráfico y el narrativo, citan la obra de Hergé desde la seriedad. Podemos definirlos como una imitación de un estilo sin la función satírica; entre estos podemos incluir los textos de segundo grado que están pensados como una continuación o extensión de una obra preexistente. Yves Rodier ha realizado diferentes pastiches/ forgeries imitando el estilo de Hergé. A través de este artículo se analizan su uso de la forgerie y el pastiche para crear obras apócrifas que pueden leerse como si formaran parte del universo oficial.

Palabras clave: apócrifo, forgerie, pastiche, Tintín, Yves Rodier.

\begin{abstract}
Among the apocryphal of The Adventures of Tintin there are those who, by imitation of the graphic and narrative style, quote Hergé's work from the seriousness. We can define them as an imitation of a style without the satirical function; among these we can include second grade texts that are intended as a continuation or extension of a pre-existing work. Yves Rodier has made different pastiches/forgeries imitating Hergé's style. This article analyzes his use of forgerie and pastiche to create apocryphal works that can be read as if they were part of the official universe.
\end{abstract}

Keywords: apocryphal, forgerie, pastiche, Tintin, Yves Rodier.

\section{Cita bibliográfica}

Pérez- Gómez, M.A. «Entre la forgerie y el pastiche: la obra tributo a Tintín de Yves Rodier», en CuCo, Cuadernos de cómic n. 15 (2020), pp. 10-30. 
«La obra de Hergé ha tenido ese privilegio de los clásicos que es el que da la imitación.» ${ }^{1}$

\section{Introducción}

Cuando hablamos de los apócrifos de Tintín normalmente nos referimos a un tipo de obras que buscan homenajear la de Hergé desde diferentes perspectivas: comedia, sátira o drama. El relato puede pasar a refundarse como un texto político, como sucede en The Adventures of Tintin: Breaking Free de J. Daniels (1988); de carácter sexual en Tintin in Thailand de Bud E. Weyser (1999); o a modo de crítica geopolítica en Tintín en Irak de Youssouf - Nqp y Víctor (2004). Si algo une a las obras anteriormente citadas es que, aparte del homenaje o la utilización de los personajes y situaciones extraídas de Las aventuras de Tintín, no tienen un fin, ni continuista ni de pertenencia al universo primario, más allá del guiño o la transformación que supone el texto final. Son un tipo de producción clandestina, a causa de la política de rechazo de Moulinsart hacia este tipo de obras.

Entre los apócrifos dedicados al periodista belga y su universo, existen algunos que buscan homenajear, tanto por imitación del estilo gráfico como por el narrativo, la obra de Hergé desde cierta pretensión continuista y de ampliación de la obra original. Intentando utilizar todas las herramientas gráficas así como las narrativas desplegadas por el autor belga. Yves Rodier es, posiblemente, el más reputado y conocido de estos autores, el que más ha dialogado con la obra de Hergé, en un de tú a tú muy desigual. Rodier nos plantea su voluntad de seguir elaborando aventuras de Tintín. Sin embargo, su planteamiento es seguir la línea marcada por Hergé e intervenir algunas de las obras originales. A través de este autor canadiense vamos a analizar el concepto de pastiche dentro el noveno arte.

\section{Una breve aproximación al concepto de pastiche}

El origen del término es literal: pastiche es una evolución de la palabra romance pasticcio, que hace referencia a un plato, una especie de batiburrillo de carne, vegetales, huevos y abierto a cualquier posibilidad de adiciones. ${ }^{2}$ Durante el Renacimiento la escena artística consideraba al pasticcio como una metáfora de la obra de aquellos

${ }^{1}$ Castillo, F. Tintín-Hergé. Una vida del siglo Xx. Madrid, Fórcola Ediciones, 2019, p. 306.

2 Battaglia, S. Grande Dizionario della Lingua Italiana. Vol. 12. Turín, Unione Tipográfica-Editrice, 1984 , p. 791. 
autores que no tienen demasiada calidad debido a los diferentes estilos que utilizan. ${ }^{3}$ Un tipo de obras en las que el pintor no deja ver su propio estilo, si no que se expresa a través del de otros.

En la Italia de dicho periodo histórico empieza a haber una gran demanda de obra pictórica por parte de la nobleza, los comerciantes y la Iglesia. Esto supone una gran oportunidad para los pintores de pastiches de autores reputados. Por lo que el pasticcio, la copia deliberada de la obra y del estilo de otro autor, se convierte en un negocio. Con ese sistema de copias se asientan los estilos de los autores más populares del momento y de aquellos que son del gusto de las clases sociales que tienen los medios para poder adquirirlas.

A lo largo del siglo xvi la práctica de pintar copias fraudulentas se ve respaldada dentro del discurso de la selección. En el centro de esa teoría está una Helena del pintor griego Zeuxis, el cual compuso la figura copiando diferentes partes de otras esculturas que representaban deidades femeninas, buscando lo mejor de cada una. ${ }^{4}$ Escoger aquellos elementos sobresalientes de las obras maestras como un acto para garantizar la aceptación de ciertos sectores del mundo del arte. Pero el rasgo definitorio, la autoría del pintor, no es propio sino ajeno, ya que el valor de la obra creada por el imitador vale tanto como su capacidad para emular el estilo de otro. Aun así, durante el Renacimiento hubo algunos de estos imitadores que adquirieron cierta fama debido a la similitud de los trazos a los de los pintores originales. Entre los más conocidos estaban Guido Reni, que mostró una gran habilidad de emular el arte de Carracci, y Sassoferrato, que hacía lo propio con la obra de Rafael. ${ }^{5}$

Hoesterey apunta que, a mediados del siglo xviI, la «apreciación por el género estaba a medio camino entre la admiración por lo magníficamente que estaba ejecutada la copia de una obra maestra, la copia fraudulenta producida para "un mercado de masas", y la recepción del pasticcio como una mezcla de estilos». ${ }^{6}$

Tres enfoques para un mismo fenómeno que podemos definir como de no-autor: el primero se refiere a la habilidad técnica del productor de la obra pictórica, la segunda supone una depreciación del pasticcio que tan solo cumple una función mercadotécnica, y, por último, como una obra no relevante que no es capaz de atenerse al estilo propio del pintor. Pero el pasticcio se abrió a un segundo mercado, que no podemos definir como anticlásico, en el que se bastardiza el conocimiento logrado por el arte

${ }^{3}$ Ibid., p. 790.

${ }^{4}$ Hoesterey, I. Pastiche. Cultural memmory, in art, film, literature. Bloomington, Indiana University Press, 2001, p. 2.

5 Ibid, p. 3.

${ }_{6}$ Todas las citas de textos han sido traducidas por el autor del artículo.

7 Idem. 
clásico reescrito durante el Renacimiento. Aquí el pastiche se considera un homenaje o la asimilación de la obra de un gran maestro, algo que era valorado positivamente. ${ }^{8}$

En Histoire de la Langue Française compilada por Brunot, se definen como «Tableaux, qui ne sont ni des Originaux, ni des Copies». ${ }^{9}$ Este filólogo sitúa el estatus incierto de los pastiches: ${ }^{10}$ no son originales por mucho que se parezcan al original, pero tampoco son copias. Hoesterey localiza una ampliación a la definición de Brunot en la edición Neufchastel de 1765 de la Encyclopédie, la obra magna de la Ilustración. En esta, se añade una coletilla a la definición ya dada: «pero están hechas con la sensibilidad y las maneras de otro pintor, con tal habilidad que los más inteligentes a veces han sido engañados». ${ }^{11}$ Habla del pastiche como aquella obra ingeniosa, o en la que el autor demuestra gran conocimiento de las técnicas de otro pintor. En el aspecto literario, Marmontel habla del pastiche literario definiéndolo como «una imitación afecta de la manera y el estilo de un escritor», ${ }^{12}$ aunque luego añade que esos autores «son capaces de asimilar la grandeza de un escritor, penetrar en su alma y su genio». ${ }^{13}$ Si bien la primera parte de esa definición es de carácter continuista con respecto a Brunot, la segunda parte parece más bien una intuición que algo comprobable a través del resultado final. Desde inicios del siglo xvi, los pastiches derivados de obras de los grandes maestros son mayoritariamente producidos para coleccionistas con y sin ánimo de lucro. El destinatario final puede ser conocedor, o no, del carácter apócrifo de la obra que adquiere. Las forgeries modernas son copias perfectas para un mercado del arte que carece de la impureza de las falsificaciones..$^{14} \mathrm{El}$ pastiche es, en estos términos, un tipo de obra «segura», que no intenta traspasar esa frontera legal.

Con la llegada del siglo xx, se empiezan a definir unos límites mucho más laxos en cuanto a la originalidad de la obra y la autoría, los pastiches comparten espacio con las obras originales y, en algunos casos, tienen más protagonismo. Para Letissier, desde los modernistas, las reescrituras son una cuestión por derecho propio que invitaba a la reflexión. ${ }^{15}$ Esta adopta múltiples formas, la cita, el préstamo, la canibalización o el simple plagio. Con la llegada de la comunicación de masas, los nuevos medios de comunicación, el sentido negativo del

pastiche es, al igual que la parodia, la imitación de un único o peculiar, estilo idiosincrático, portar una máscara lingüística, un discurso en una lengua muerta. Pero es una práctica

\footnotetext{
${ }^{8}$ Ibid., pp. 3-4.

9 Brunot, F. Histoire de la Langue Française des Origines à Nos Jours. Vol vi: le Xviır siecle. París, Librairie Armand Collin, 1966, p. 718.

10 En Francia, pasticcio cambia su escritura por pastiche.

${ }^{11}$ Hoesterey, I. Op. Cit., p. 6.

12 Ibid., p. 7.

13 Idem.

14 Ibid., p. 11.

15 Letissier, G. Rewriting/reprising plural intertextualities. Newcastle, Cambridge Scholars, 2009, p. 4.
} 
neutral que solo busca la mimesis, sin los motivos ulteriores de la parodia, amputando el impulso satírico. ${ }^{16}$

La búsqueda de un estilo personal e intransferible está en quiebra, asumir discursos ajenos como propios, el discurso de la imitación y de la apropiación como un reconocimiento que para muchos espectadores, lectores u oyentes, puede ser considerada como un resultado y una actividad más valorable que el desarrollo de un estilo propio por parte de un artista.

Podemos suponer que el punto de partida de los pastiches es realizar una cita, aunque «una cita es a un mismo tiempo expresión de la legitimidad previa de algo superior que la sostiene y acto de legitimación de dicha autoridad producida por su mero ejercicio». ${ }^{17}$ Esta legitimización de lo previo nos hace pensar en un texto derivado, y en la jerarquía de los mismos. Sin embargo, dentro de la cultura de masas estos productos pueden ocupar un lugar preferente entre los gustos de un público menos formados en cuestiones de arte. Sánchez-Biosca lo formula de la siguiente manera:

los productos de consumo de masas más seriados y dirigidos a públicos menos cultivados en el arte se cargan de un virtuosismo sin precedentes, de multiplicidad de ecos, referencias, que pese a permanecer a menudo irreconocidos, no arruinan con una ostentación intelectual su carácter más gastronómico y aparentemente banal. ${ }^{18}$

Casi todas las aproximaciones al pastiche vistas en este breve resumen tienen como punto en común el virtuosismo de los pintores imitadores a la hora de realizar una obra con el estilo de otra persona, de forma que el mayor mérito es asemejarse a otro, hasta el punto de no poder reconocer si es la obra de un gran maestro o de un maestro imitador.

\section{Pastiche y forgerie según Genette}

Hasta el momento se ha mostrado la percepción desde el ámbito teórico del pastiche como una práctica no del todo creativa, centrada en el estilo y la habilidad de los pintores. Pero el pastiche es un tipo de producción artística que relaciona un texto primario con uno terciario, que no deja de ser una visión subjetiva de un autor no canónico. Genette denomina hipertextualidad a la relación que une un «texto B (hipertexto) a un texto anterior A (hipotexto) en la que se injerta de una manera que no

${ }_{16}$ Ibid., p. 17.

17 Sánchez-Biosca, V. Una cultura de la fragmentación. Pastiche, relato y cuerpo en el cine y la televisión.

Valencia, Filmoteca de la Generalitat Valenciana, 1995, p. 23.

18 Ibid., p.25. 
es comentario»; $;^{19}$ el texto derivado se genera "por transformación simple o por transformación indirecta (imitación)». ${ }^{20}$ La primera «evoca más o menos explícitamente, sin la necesidad de hablar de él [del texto] o citarlo», ${ }^{21}$ mientras que en el caso de la imitación necesita de un contexto genérico «capaz de engendrar un número indefinido de performances miméticas». ${ }^{22}$

Genette plantea un esquema en el cual enumera tres regímenes de textos: lúdico, satírico y serio. Y, por otro lado, la relación de estos con el hipotexto, que puede ser de transformación o de imitación. ${ }^{23}$ Para este artículo vamos a focalizar en aquellas relaciones de imitación, principalmente en el pastiche y la forgerie. En el régimen lúdico, en relación con la transformación, tenemos la parodia, que se ha de realizar sobre obras que sean lo suficientemente conocidas como para que el texto (resultante) sea lo bastante reconocible. En función de la relación obtendríamos un pastiche como «la imitación de un estilo sin la función satírica». ${ }^{24}$

En cuanto a la imitación seria, que Genette denomina forgerie, tiene como función principal la continuación o extensión de una obra preexistente: ${ }^{25}$ por un lado, estaría la prolongación de un texto que en principio está cerrado; por el otro, la continuación, en el cual la obra previa estaba definitivamente abierta. ${ }^{26}$ Esta característica es la que da forma al autor al que vamos a analizar, tanto por la imitación de estilo más propia del pastiche, y el afán de continuación y prolongación del texto primario por parte de este.

$\mathrm{El}$ análisis que Genette hace sobre los textos de segundo grado se centra en las variaciones de textos en el ámbito de la literatura. En el caso del cómic, arte basado en la reproducción serial en masa, tendremos que advertir que hay diferentes elementos que lo componen. La narrativa, la forma de contar del autor original, tiene que ser trasladada a esos nuevos proyectos, la estructura del relato es muy importante sobre todo en Las aventuras de Tintín; la expresión de los personajes, el layout de página, el trazo del dibujo, el color y los escenarios. Sin olvidarnos del formato álbum o el diseño de las portadas. Así pues, en el noveno arte tanto el pastiche como la forgerie tienen una complejidad añadida. Aspecto que se acentúa en el caso de Hergé, ya que es el único dibujante de la colección y el trazo empleado por este es muy característico.

${ }_{19}$ Genette, G. Palimpsestos. La literatura de segundo grado. Madrid, Taurus, 1989, p. 14.

${ }^{20}$ Ibid., p. 17.

${ }^{21}$ Ibid., p. 14.

${ }^{22}$ Ibid., p. 15.

${ }^{23}$ Ibid., pp. 40-41.

${ }^{24}$ Ibid., p. 38.

${ }_{25}$ Ibid., p. 104.

${ }^{26}$ Ibid., p. 201. 


\section{Hergé y el problema de la continuidad frente a la producción del fandom}

Uno de los rasgos editoriales que caracteriza Las aventuras de Tintín es que, a pesar del éxito cosechado a lo largo de décadas, no tiene continuidad oficial. En el caso de otros títulos con gran popularidad dentro de la Bande Dessinée, como Lucky Luke, Spirou, Blake y Mortimer o Los Pitufos, las aventuras han tenido continuidad más allá de los creadores originales. De hecho, no existe ningún impedimento legal que imposibilite que a las aventuras del joven reportero belga se le sumen nuevos álbumes con otras aventuras, tan solo unas declaraciones que el propio Hergé realizó a Numa Sadoul en su serie de entrevistas:

¿Sin mí? Bueno, sinceramente, no lo creo. Por supuesto, hay muchas cosas que mis
colaboradores pueden hacer sin mí e incluso mucho mejor que yo. Pero para hacer que
Tintín viva, para hacer que Haddock, Tornasol, los Dupondts, todos los demás vivan, creo
que soy el único que puede hacerlo: Tintín (y todos los demás) soy yo, exactamente como
Flaubert dijo: «Madame Bovary, soy yo» [...] Si otros usaran a Tintín, podrían hacerlo
mejor, tal vez menos bien. Una cosa es segura: ¡lo harían de manera diferente y, de repente,
ya no sería Tintín! ${ }^{27}$

En la actualidad, Moulinsart S.A. es la empresa gestora del patrimonio intelectual de Hergé. En la página comercial sobre Tintín gestionada por esta empresa, podemos encontrar un documento sobre la utilización de la obra de Hergé en Internet. Se trata de un texto donde se regula la comercialización de todos los productos relacionados con Tintín, y las posibles sanciones por el uso fraudulento o con ánimo de lucro de estos contenidos. Pero en el primer artículo de este reglamento podemos ver que no es solo la comercialización sino sobre el uso de los elementos distintivos de la obra de Hergé:

Los derechos de autor protegen no solo los cómics y los dibujos (cajas, tiras, láminas, dibujos insertados, portadas), textos, diálogos, gags, sino también los escenarios, los personajes y sus características, nombres, títulos y lugares imaginarios, onomatopeyas, fuentes y otros elementos de la obra de Hergé. ${ }^{28}$

En resumen: las narrativas creadas por Hergé. Escenarios, personajes, diálogos, gags: los podemos considerar como existentes de su obra al estar definidos con unas características propias. Los existentes son todos aquellos elementos con los que el creador construye el universo. Desde personajes, vehículos, edificios, formas sociales, etc. ${ }^{29}$

27 Sadoul, N. Tintin et moi, Entretiens avec Hergé. París, Casterman, 1983, pp. 45-46.

${ }^{28}$ Charte d'utilisation de l'œuvre d'Herge sur internet. http://fr.tintin.com/plus/ring/charte.html

29 Pérez-Gómez, M. Á. «Analizando Neurope: la construcción de mundo en la obra de Miguel Ángel Martín». CuCo, Cuadernos de cómic n. ${ }^{\circ}$ 6, 2016, p. 36. Disponible en: http://cuadernosdecomic. com/docs/revista $6 /$ Analizando $\% 20$ Neurope $\% 201 \mathrm{a} \% 20$ construccion $\% 20 \mathrm{de} \% 20$ mundo $\% 20 \mathrm{en} \% 20$ la $\% 20$ obra $\% 20$ de $\% 20$ miguel $\% 20$ angel $\% 20$ martin.pdf 
Los textos sujetos a esta condición de archivo de existentes manifiestan su carácter arcóntico.

Lo arcóntico se relaciona con el archivo de palabras, lo tomo de la obra Mal de archivo de Jacques Derrida de 1995, en la que Derrida afirma que todos los archivos permanecen abiertos a nuevas entradas, nuevos artefactos, nuevos contenidos. Ningún archivo es definitivo, completo, cerrado: al incorporar el conocimiento desplegado en referencia a él, el archivo aumenta, se absorbe, gana auctoritas. ${ }^{30}$

Esta consideración pone a la obra de Hergé en un estatus interesante. A eso hay que sumarle que Tintín y el Arte-Alfa (1987) era la obra que iba a cerrar las aventuras del reportero belga, pero quedó inacabada. Por lo que podemos entender que no solo el álbum en cuestión, sino todas las aventuras, están incompletas, por lo que estamos ante una obra abierta, que en ningún momento ha tenido una clausura. Si a eso le sumamos ese carácter arcóntico, de ser una obra de la cual podemos extraer diferentes existentes, se puede considerar que Las aventuras de Tintín es una obra abierta. No solo a la interpretación del lector, sino también por la carencia de un cierre claro.

Para Eco la obra siempre está abierta, aunque esté finalizada por el autor, pero para poder cerrarla por uno mismo hay que tener un conocimiento previo. No vale con enfrentarse a ella desde el absoluto desconocimiento sino que el autor tiene en cuenta «el background cultural de una decisión formativa [...] la visión del mundo que ella supone». ${ }^{31}$ Poseer un capital cultural que permita operar a los autores de pastiches en las mismas coordenadas que el autor original no solo conociendo como este articula la ficción, sino también el trazo y el proceso de creación.

\section{Yves Rodier y la búsqueda de un Hergé canónico sin Hergé}

Una vez vista la breve evolución histórica del concepto de pastiche, el estatus como propiedad intelectual de Las aventuras de Tintin y cómo podemos concebir esta colección como una obra abierta, vamos a analizar las incursiones de Yves Rodier en el universo de Tintín.

Rodier nace el 5 de junio de 1967 en Farnham (Quebec). Desde muy temprana edad empieza a dibujar gracias al interés que despiertan en él los álbumes de Las aventuras de Tintín y los de Astérix de René Goscinny y Albert Uderzo. Durante su infancia es un ávido lector de los cómics de los años cincuenta y sesenta descubiertos en las

\footnotetext{
30 Derecho, A. «Archontic Literature.A Definition, a History, and Several Theories of Fan Fiction», en Hellekson, K. y Busse, K (eds.). Fan Fiction and Fan Communities in the Age of the Internet. McFarland \& Company Inc., 2006, p. 64.

31 Eco, U. Obra abierta. Barcelona, Editorial Ariel, 1990, p. 197.
} 
antiguas colecciones del Journal Tintin y Spirou de su hermano, y por Pif Gadget, que su padre le compraba cada semana. La publicación del cuaderno de bocetos de Hergé para la última aventura inacabada de Tintín (Tintín y el Arte Alpha), en 1987, hace que Rodier se plantee, con tan solo diecinueve años, acabar la obra iniciada por Hergé, trabajo en el que estuvo inmerso durante cinco años. ${ }^{32}$ Esa dedicación se debe en gran medida a que Rodier no va a hacer un álbum con su estilo, si no intentando asimilar el trazo de Hergé.

A pesar de que el propio Rodier ha dibujado y guionizado series propias, sigue siendo más reconocido por su trabajo de reimaginación de un Hergé canónico. Entre sus obras están los dos álbumes de Pignouf et Hamlet, los tres de Simon Nian, con guion de François Corteggiani, El Spectro, con guion de Frédedic Antoine, publicados por Le Lombard con cuatro álbumes y su último trabajo, en esta ocasión como guionista, es Purgatoire con un solo álbum.

Aun así, su trabajo de reescritura de Las aventuras de Tintin suscita un interés para el investigador, ya que nos muestra el pastiche en un contexto muy diferente al representado por los estudiosos de este tipo de textos derivados. El sentido de cada uno de los pastiches/forgeries que se va a analizar tiene unos rasgos distintivos propios. Estos títulos operan en un espacio de comprensión muy diferente al que lo hacen las obras originales. Los lectores deben ser conocedores de la obra previa ya que la lectura de estos trabajos implica, en primera instancia, poder ver aquellos aspectos que los igualan a los textos primarios, los que se diferencian y las citas que apelan a los tintinófilos conocedores de todo lo que rodea y compone este universo.

\section{La forgerie en las reescrituras de Yves Rodier}

Todas las obras que se van a analizar a continuación están relacionadas directamente con la obra de Hergé en diferentes grados, desde finalización de proyectos, hasta desarrollo de insertos pasando por intentos de hacer álbumes a partir de ideas descartadas por el propio Hergé. Constituyendo un claro ejemplo de cómo muchos fans quieren formar parte del universo original o estar vinculados de alguna manera.

Tintin et l'Alph-Art (1986)- B/N y (Les Arumbayas,1991)- Color

Tintin y el Arte-Alfa iba a ser el último álbum de Las Aventuras de Tintín. Tanto por los bocetos como por el guion publicados por Casterman en 1986, sabemos que fue concebida como una gran reunión final. Un caso en el que iban a tener presencia dife-

32 Rodier, Y. «Tintín», en Yves Rodier Illustrateur. Disponible en: https://web.archive.org/ web/20021205023140/http://www.geocities.com/yves rodier/tintin.html 
rentes personajes secundarios aparecidos en álbumes anteriores. Una fiesta de despedida inacabada en la que cualquier fan acérrimo de la colección le gustaría participar. Tras el fallecimiento de Hergé, con un material que no era posible editar en forma de álbum, la viuda del autor tenía tres opciones: la primera pasaba por que otro autor finalizase el cómic: en este caso, el candidato más claro era Bob De Moor; la segunda consistía en publicar el material existente; y la tercera era olvidar el proyecto. ${ }^{33}$

La publicación del casi-álbum póstumo descubre al público la forma de trabajar de Hergé, a la vez que desalienta a muchos de los seguidores del reportero belga. Son cuarenta y dos páginas abocetadas acompañadas del guion. Una vez desechada la opción de hacer el encargo a otro dibujante, la obra queda en el aire. Aquí podemos retomar la idea de la obra abierta como una oportunidad para supuestos aspirantes a suceder al padre de Tintín.

Lo publicado nos cuenta un caso que tiene como trasfondo el mundo del arte contemporáneo. Una mañana cualquiera en el Castillo de Moulinsart nos encontramos con que el capitán Haddock está soñando de manera premonitoria con la Castafiore. Cuando despierta la cantante lo llama por teléfono. Tintín se pone al teléfono y la soprano le comunica que va a pasar un par de días en Bélgica, que quiere quedar con ellos para luego irse de vacaciones con el popular mago Endaddine Akass. Haddock sale a dar una vuelta y se encuentra con Castafiore; para evitarla, se refugia en una galería de arte, pero, poco después, entra ella. Allí conoce a Ramo Nash, creador del Arte-Alfa. Entre este y la cantante le convencen para comprar una escultura de una hache mayúscula. Por su lado, el propietario de la galería quiere hablar con Tintín y concierta una cita a la que no asiste. Al día siguiente, lee en la prensa que ha fallecido en un accidente de tráfico; esta muerte coincide con la de otro experto en arte. Tintín sospecha algo y se dirige a la galería a investigar. Cuando va de camino a ver el lugar del accidente un par de tipos en coche intentan asesinarlo. De vuelta a casa se da cuenta de que el mago amigo de Castafiore porta una joya igual que la de la recepcionista de la galería de arte. Van a ver una actuación del supuesto mago y descubren que es un timador que vende baratijas como amuletos magnetizados. Tintín y Haddock se dirigen a Ischia, lugar de reposo de Castafiore y Akass, siguiendo una pista para resolver los crímenes. Entre los invitados se encuentra con Ramo Nash. La historia finaliza cuando Tintín descubre que todo es una trama de falsificación de arte. Es atrapado, y en las últimas viñetas vemos como los secuaces de los falsificadores lo conducen pistola en mano para ejecutarlo. ${ }^{34}$

Llegados a este punto, la historia queda abierta. El primero que se ofrece a la Fundación Moulinsart para finalizar el álbum es Rodier. Se compromete a respetar por completo el original, pero desde la Fundación se rechaza la oferta. Ese fue el pis-

33 Castillo, F. Op. cit., p. 307.

${ }^{34}$ Hergé. Tintín y el Arte-Alfa. Barcelona, Editorial Juventud, 2016, p. 53. 
toletazo de salida para que muchos, como Rodier, decidiesen acabar este título por cuenta propia. ${ }^{35}$ Presenta el álbum completo en blanco y negro respaldado por Bob de Moor; tras el fallecimiento de este, Rodier redibuja todo el álbum aproximándolo al estilo de Hergé. ${ }^{36}$ La historia se retoma a partir del momento en el que Tintín es conducido a una sala en la que va a convertirse en una escultura bajo una capa de poliuretano líquido. Se libra gracias a la intervención de Haddock y Milú y, a partir de ahí, se narra la peripecia final en la que se resuelve el relato. Huyen pero son atrapados y puestos a disposición de unos falsos policías. Cuando van a ejecutarlos, Endaddine Akass confiesa ser Rastatopoulos, villano recurrente en este universo ficcional. El último escenario de la acción es un acantilado donde, tras un forcejeo, Tintín pierde el conocimiento y tiene un sueño surrealista protagonizado por Milú. En un último intento, Rastatopoulos intenta ahorcar a Tintín y Haddock, pero finalmente es él quien muere despeñado. En ese momento, aparece Ramo Nash que confiesa ser un falsificador, pero que no comparte los métodos del villano recién fallecido. A la vuelta, tras resolver el misterio, Martina Vandezande, la recepcionista de la galería, ha ido a recibir a Tintín para pedirle si está disponible para presentárselo a sus padres. El álbum finaliza con un gag en el que intervienen Ramo Nash, que está esculpiendo una figura en piedra de Haddock como dios romano; también aparece Serafín Latón, otro personaje recurrente.

En el prólogo de las diferentes ediciones pirata de este trabajo, Rodier expresa que no se trata de un álbum original, sino de su versión de lo que podría haber sido dicho volumen. También manifiesta haber estudiado la forma de trabajo de Hergé para poder aplicarla, pero que también se ha centrado en el estudio de los existentes narrativos, textuales, paratextuales y visuales. La aparición de Rastatopoulos y Serafín Latón anclan este apócrifo al texto primario, y Rodier se toma la licencia de emparejar al reportero belga con una de los personajes creados por Hergé para este álbum. Este proyecto es una prolongación de un texto no finalizado, una reimaginación de un final inexistente a partir de las pautas desarrolladas por Hergé a través de los veintitrés álbumes publicados. Esta obra es una forgerie en el sentido estricto de la palabra. Es una imitación seria, tan seria que, aunque no sea la intención, es una suplantación de los bocetos del autor original.

\section{Une aventure de Tintin reporter pigiste au XXe siècle (¿1995?)}

Si bien el título anterior sigue unas pautas muy claras sobre la forma y el fondo del relato, los autores apócrifos juegan con los tipos de formatos de publicación, quizás

35 Existen diferentes versiones de este álbum. Antes de la reescritura de Rodier apareció otra firmada por un tal Ramo Nash en 1988 y entre 1988 y 1989 la Escuela Superior de Bellas Artes de París publico otra en CD-Rom.

36 Ibid., p.319. 
en un acto que invita a pensar que la apropiación del texto es mayor cuando uno de estos creadores sitúa el texto primario en un contexto visual diferente, haciendo que un personaje como Tintín siga funcionando como tal. El punto de partida de esta adición ideada por Rodier es un guion propuesto en el número 1027 (19 de diciembre de 1957) de la revista Spirou, que en aquellos momentos era la publicación competidora del Journal de Tintin. Une aventure de Tintin reporter pigiste au xxe siècle trata de cómo Tintín consigue su primera gran misión como reportero de Le XXe siècle, el viaje al país de los Soviets. Para ello, Rodier adopta un formato diferente al de los álbumes. La orientación del papel es a la francesa: la viñetas se reparten en forma de tiras de tres o cuatro viñetas, con dos tiras por página.

Mientras Tintín pasea con Milú, se encuentra con un delincuente sospechoso de ser el autor de un atraco reciente. Los protagonistas cogen un taxi y lo siguen hasta un restaurante. Contactan con la policía y lo detienen. Mickey Martino, el atracador, asegura que acaba de llegar de Italia. Lo acompañan a su piso donde el casero dice que no ha entrado nadie en los últimos días. Pero, gracias al despertador, Tintín consigue la pista definitiva para atraparlo. En la última página le descubre el secreto de la detención al director del periódico, y este, augurándole un buen futuro, lo manda al país de los Soviets, primer álbum de Las aventuras de Tintin.

Al final de la historia, nos encontramos el anclaje al universo ficcional de Tintín. El título de Tintín en el País de los Soviets es tan poderoso en este universo, que no solo lo fija al canon, sino que también lo sitúa cronológicamente a modo de precuela. Para Wolf, la precuela es una historia que sucede antes del texto original; actúa como trasfondo de esa obra y reposa en el conocimiento de la audiencia. ${ }^{37}$ Pero no solo de Tintin en el país de los Soviets sino de todas Las aventuras de Tintin. En una última modificación, el canadiense colorea la última página. ${ }^{38}$

\section{Un jour dans un aeroport (Rascarman, 1996)}

Si en la obra anterior el anclaje es el título del primer álbum de Tintín a modo de precuela, tras ella Rodier vuelve a probar con otro proyecto de Hergé sin finalizar. Tras la publicación de Tintín y los picaros (1976), Hergé empieza a trabajar en una idea para una aventura que va a tener como única localización una terminal de aeropuerto. En una de las entrevistas con Sadoul, el autor belga declara:

${ }^{37}$ Wolf, M. J. P. Building imaginary worlds: the theory and history of subcreation. New York, Routledge, 2013, p. 207.

${ }^{38}$ Existen dos versiones coloreadas a partir del trabajo de Rodier, una creada por el Studio Juhis, pero maquetada en un A4 en vertical, y otra sin referencia de autor, cuyo coloreado está realizado con una textura de cera de colores. 
Me gustaría que todo sucediera en un aeropuerto, de principio a fin. El aeropuerto es un centro rico en posibilidades humanas, un punto de encuentro de diversas nacionalidades; ¡todo el mundo se reduce, en un aeropuerto! Allí, puede pasar cualquier cosa, tragedias, gags, exotismo, aventura... Entonces tengo un lugar, todavía tengo que encontrar una historia, un tema de inicio, una trama. ${ }^{39}$

Finalmente, Hergé no la encontró. En L'univers d'Hergé - croquis, projets, histoires inachevées (Rombaldi, 1988), aparecen bocetos y sinopsis previos de este proyecto inacabado. Se percibe que va a ser un relato de vidas cruzadas en el que van a aparecer personajes que ya habían acompañado anteriormente, para bien o para mal, a Tintín en sus aventuras.

Siguiendo con ese afán continuista y completista, Rodier se plantea realizar una aventura completa a partir de los conceptos del creador original. La idea inicial es realizar un álbum de sesenta y dos páginas desarrollando lo publicado por Rombaldi. Sin embargo, el autor canadiense tan solo dibuja una página, que primero publica en blanco y negro y luego a color. En ella, vemos a Tintín en el aeropuerto por motivos desconocidos, y allí se encuentra al general Alcázar con ropa de civil. Justo antes de darse la mano, el general recibe un disparo; Tintín atiende un momento al militar y emprende la persecución del tirador. En la penúltima viñeta se acerca un hombre que está llamando desde una cabina telefónica y que viste igual que el que cree que es el delincuente. Ese hombre es el periodista Jean-Loup de la Batellerie, este personaje aparece en Las joyas de la Castafiore (1963). En la última viñeta vemos en segundo plano a Tintín de espaldas buscando al responsable del disparo y, en primer plano, un hombre calvo y con perilla mirando de reojo a Tintín y sonriendo con satisfacción.

La vinculación de esta página parte, por un lado, del desarrollo de una idea abandonada por Hergé y, por otro, de la utilización de personajes a modo de existentes narrativos que unifican el universo narrativo. En este caso, el general Alcázar, que aparece previamente en tres álbumes, y el periodista citado anteriormente, que aparece en otro. Aunque existe además un elemento extratextual, un documento publicado en una de las ediciones piratas ${ }^{40} \mathrm{y}$ muy limitadas de este trabajo del canadiense. En él, no solo podemos ver la página a color y en blanco y negro; también se muestran bocetos y diseños de personajes. Entre la documentación se encuentra una carta fechada en noviembre de 1996, en la que Rodier habla de sus intenciones: «Incluso antes de terminar el Arte-Alfa en 1991, comenzaba a elaborar el escenario para esta 25. a aventura de Tintín, con la firme intención de abordarlo tan pronto como se completara el curso del proyecto...». ${ }^{41}$ Es decir, no es solo la utilización de un concepto descartado de Hergé y de algunos personajes recurrentes o ya aparecidos en este universo ficcio-

\footnotetext{
39 SAdoul, N. Op. Cit., p. 122.

40 Concretamente, la editada por Rascarman en 1996.

${ }^{41}$ Rodier, Y. Un jour dans un aeroport. Rascarman, 1996, s.p.
} 
nal, sino la intención de que este sea el álbum número 25 de Las aventuras de Tintín. Algo que define cierto grado de pretensión canónica por parte de Rodier.

\section{Tintin en el Tíbet-página 27bis (sin datar)}

Hasta el momento, hemos visto: una finalización de un relato inacabado, una obra original conectada cronológicamente con el universo original y un intento de álbum ideado a partir de los bocetos e ideas del autor original. En esta ocasión, Rodier decide intervenir directamente en una obra acabada. Tintín en el Tíbet (1960) es el vigésimo álbum de Las aventuras de Tintin. En él, el reportero se dirige a Asia para acudir al rescate de Tchang Tchong-Jen, compañero de aventuras local en El loto azul (1935), al ser uno de los desaparecidos en un accidente aéreo.

Rodier introduce un guiño a los lectores en su página 27bis, pero con la característica de que encaja entre la última viñeta de la página 27 y la primera de la 28. Este añadido altera la cronología del relato original sumando un día más a la aventura: la expedición hace noche en la montaña, mientras que en el original siguen en la ruta. Por la noche, el autor nos mete dentro de la tienda de campaña compartida por el capitán Haddock, Tintín y Milú; nos muestra a un Tintín impaciente por saber qué ha sido de su amigo Tchang. En mitad de la noche, oye ruido fuera; creyendo que alguien ha salido de su tienda de campaña, sale de la suya para investigar. Milú empieza a ladrar, como consecuencia. Tintín presta atención a una figura humanoide huyendo en dirección contraria a la que están acampados los protagonistas. A continuación, en un plano entero frontal de Tintín con la tienda de campaña de fondo, mirando en la profundidad de la noche, este piensa: «i之Este es el famoso yeti?!... Es mejor no hablar de eso, la situación ya es difícil...». En la última viñeta ya es de día y vemos al grupo emprender la expedición de nuevo enlazando con la primera viñeta de la página 28.

La viñeta en la que Tintín decide no decir nada es una puesta a cero de este inserto, que deja que encaje a la perfección sin alterar la trama del relato original. A pesar de que el Yeti vuelve a aparecer de manera soslayada en la página 31 y de forma más explícita en la 55. Se trata de un tipo de ampliación diegética que podemos denominar de dos formas. Podemos considerar este inserto como una escena perdida. Estas consisten en «incidentes, conversaciones, interacciones, que tienen lugar dentro de la escala de tiempo del canon». ${ }^{42}$ Se trata de acciones que pueden haber sucedido pero no se han mostrado de manera explícita y que rellenan huecos dejados en el texto primario. Para Wolf, este tipo de contenidos añadidos a una narrativa principal y cerrada, es una mediocuela. Un tipo de relato que se caracteriza por estar situado entre historias ya existentes y ese rasgo cronológico es su característica definitoria. Esta

${ }^{42}$ Pugh, S. The Democratic Genre. Fan Fiction in a Literary Context. Bridgend, Poetry Wales Press Ltd, 2005, p. 57. 
categoría se divide en dos: intercuelas e intracuelas. La primera sucede entre dos narrativas, por ejemplo dos álbumes de Las aventuras de Tintín, y la segunda tiene lugar en un hueco de una única obra. ${ }^{43}$ Por lo que Tintín en el Tíbet-página $27 b i$ es una intracuela de Tintín en el Tíbet.

\section{Le Thermozéro (sin datar)}

El siguiente apócrifo en el que trabaja Rodier ratifica uno de los aspectos que hace que el autor canadiense se decida por trabajar con una obra u otra de Hergé: que hayan sido proyectos con cierta significación dentro de su obra artística. En este caso es la primera vez que Hergé trabaja con el guion de otra persona.

Al igual que Un jour dans un aeroport, Le Thermozéro es otro de esos proyectos desechados por Hergé. Aunque de este existe más información, en la biografía sobre el autor escrita por Pierre Assouline se habla de este proyecto como algo inédito. Por primera vez, contrariamente a sus principios, Hergé está dispuesto a trabajar con otros autores. Del guion se ocuparía Greg, seudónimo de Michel Regnier, que había colaborado en Spirou y la revista Tintín. De este proyecto existen una sinopsis, un borrador del guion y seis páginas abocetadas con los diálogos, bocetos de personajes y anotaciones. La trama central de este relato gira en torno a una botella que contiene un producto mortal: se especula con unas píldoras atómicas que alguien se ha llevado por error. Tintín seguirá a esa persona y se incorpora a la acción justo en el momento en que la manipulación de ese objeto va a producir una gran catástrofe. ${ }^{44}$ Pero Hergé abandona el proyecto porque lo considera tan elaborado y preparado que ahogaba su capacidad de improvisación. ${ }^{45}$

En las páginas de Hergé se muestra a Tintín y al capitán Haddock en coche en un día lluvioso, el vehículo patina en el asfalto mojado y se sale de la carretera. Este accidente desembocará en otros, a causa de los cuales, de manera cómica, el capitán será golpeado por algunos vehículos. Una vez reemprenden el camino ven como el coche que va delante se sale de la carretera violentamente: nuestros protagonistas irán al rescate del conductor, un hombre que parece perseguido por dos hombres misteriosos.

En esta ocasión, la intervención de Rodier se practica directamente sobre el trabajo de Hergé. Acaba en blanco y negro la página número $4,{ }^{46}$ en la que Tintín y Haddock paran para ayudar al accidentado. Rodier conserva la parrilla de viñetas, las compo-

${ }^{43}$ Wolf, M. J. P. Op. Cit., p. 207.

44 Assouline, P. Hergé. París, Gallimard, 1996.p. 544.

45 Ibid. P. 546.

${ }^{46}$ Ralph Edenbag, otro autor de apócrifos de Tintín, entintó y coloreó las páginas 2, 5 y 6. 
siciones, las acciones, los diálogos y todos aquellos elementos característicos y pertenecientes a la biblioteca de recursos visuales de Hergé. A pesar de que la intención pudiera parecer la misma que en Un jour dans un aeroport, se asemeja más a una parte de su Arte-Alpha. Aquí el trabajo del canadiense se subyuga a una dinámica ajena, y resulta más caligráfico con respecto al original. Posiblemente, es en el que menos puede desarrollar su visión de Tintín.

\section{Rodier y el pastiche}

Si todas las obras analizadas en el bloque anterior dependen directamente del trabajo de Hergé, las que siguen a continuación son una serie de relatos en los que Yves Rodier crea nuevas, pero breves, aventuras de Tintín. Aunque integradas en el discurso visual y narrativo de Hergé. En estas se muestra el carácter arcóntico de Las aventuras de Tintin.

\section{Le lac de la sorciere (Éditions Hommage, 2003)}

Este es un pequeño relato en el que Tintín y Milú van de acampada a la campiña francesa y deciden pasar la noche cerca de un río. Cuando van al supermercado del pueblo a comprar unos víveres, Milú se pone a gruñir al ver lo que parece la cabeza de un monstruo en el almacén. El dependiente le explica que está basado en una estrambótica leyenda local que habla de un monstruo que habita en el río, precisamente cerca de donde ha acampado el reportero belga. Tintín compra la cabeza de la bestia para decorar el castillo de Moulinsart, y se dirige al lugar donde tienen la tienda de campaña. La primera noche cree ver al monstruo, a la segunda decide cambiar de lugar para poder observar correctamente que es lo que realmente sucede. La obsesión es tal que se queda dormido y sueña con la bestia. Los ladridos de Milú lo despiertan, ve una figura extraña en la penumbra y empieza una persecución. Finalmente se trata de dos vecinos del pueblo que trafican con alcohol.

Este relato de siete páginas entronca en lo visual y lo narrativo con el canon de Hergé. Es un pastiche, con un tono cómico; no busca encajar en dicho universo, como sucede con las obras anteriormente analizadas. En este relato Rodier se convierte en un autor subrogado. Todo lo que vemos es en esencia Hergé, aunque lo firme Rodier: la autoría del primero solapa cualquier logro del segundo.

La única parodia dibujada por Rodier es Destination Hollywood (2011), con guion de Antoine, en la que el autor canadiense aprovecha el estreno de la película de animación, Las aventuras de Tintin: El secreto del unicornio (2011). La trama es sencilla: Haddock se entera de que Spielberg tiene la licencia para rodar tres aventuras nuevas de Tintín. De manera que el reportero y el capitán se dirigen a Hollywood a quitár- 
selo de la cabeza. Son cinco páginas y una portada, en las que se producen una serie de guiños continuos tanto a la filmografía de Spielberg como al universo de Tintín, en forma de parodia amable.

El último gran grupo de pastiches de Rodier está compuesto por una serie de portadas de aventuras inexistentes, ilustraciones y postales de Navidad. Redibuja la portada de Tintín et le lac aux requins, con cierta inspiración en La gran ola (1830-1833) de Hokusai, y una viñeta de la página 45, a partir de la versión para prensa franco-belga, publicada entre 1972 y 1973, supervisada por Bob de Moor y Greg; la portada de Voyage à Londres en la que Tintín, Milú, Haddock, Tornasol y Nestor imitan a The Beatles en la portada de Abbey Road (1969); Le secret des Arumbayas, con ecos a álbumes originales, en la que se nos plantea una supuesta aventura en la selva; Tintin à Quebec (2000), que primero fue una tarjeta de felicitación de Navidad, luego una falsa portada y por último la cubierta de una recopilación de pastiches canadienses; Les entrailles du Llulliallaco, en la que se muestra al capitán y al reportero en la entrada de una cueva en la que se ven restos de una civilización antigua; y Le chat de la bonne volonté (1996), una postal de navidad con una pequeña historia, en la que Tintín, Haddock y Milú encuentran a un gato en la nieve, lo llevan a la iglesia y lo ponen a resguardo en el belén.

\section{Conclusiones}

Las forgeries analizadas nos muestran que estos textos funcionan a través de las referencias, y no serán nunca obras iniciáticas, sino para iniciados. Esta afirmación se basa en que son trabajos que están muy pegados al texto original, como continuación, inserto, recreación o con cualquier modelo de reescritura. No se pueden entender en su complejidad si no se conoce la obra anterior. Eso da lugar a que el texto primario siempre sea muy reconocible y significativo. En cuanto a los pastiches, Rodier los establece como un pequeño juego en el que, siguiendo las pautas originales, permite ver al personaje en distancias más cortas.

El trabajo de Rodier a partir de Hergé refleja uno de los principales rasgos del pastiche y la forgerie: el talento del autor original no deja ver el del que está haciendo la obra creada por imitación. Rodier suple esas carencias, no se trata de una obra destinada a comerciar con ella, sino a un público que va a agradecer los guiños que uno de los suyos vaya a utilizar. En ese sentido, el capital cultural se ve reflejado en la complejidad con la que la apropiación ha sido realizada: por un lado la habilidad técnica, por otro el conocimiento enciclopédico de la obra de Hergé y por último conocer el texto desde dentro. Es ahí donde la apropiación encuentra un público que cada vez absorbe más contenidos de autores no originales. 
La autoría en estos casos suele ser algo complejo. Si bien Rodier establece relatos propios, lo hace a través de las dinámicas creativas de otro. Pero el autor canadiense nos plantea un reto: firma sus obras, es reconocido por los seguidores habituales de Tintín, incluso existen variaciones por parte de otros de su trabajo. Dicho de otro modo, Rodier es, en cierto sentido, como autor de pastiches y forgeries, un autor de referencia para otros autores subrogados, con una gran reputación dentro de este universo.

Partiendo de este análisis de los apócrifos realizados por Rodier, no debemos entender estas obras como una práctica lucrativa, tal y como sucedía en los orígenes del pastiche, sino como una muestra de afecto hacia un texto concreto y la demostración de recursos y estilo del que hacen gala los autores de estas obras. Cada una de estas obras es una carta de amor con la que Rodier establece un diálogo, muy íntimo y personal, con un texto primario que conoce a la perfección: los trazos, los gags, los personajes, los escenarios, las tramas, etcétera. De manera que la mejor forma de hablar con los originales es utilizando las mismas herramientas. Y, por último, como parte de esa manera de entender el diálogo en el arte, el uso de personajes recurrentes en todas sus obras no solo establece un anclaje con la obra original, sino que busca una conexión directa que permita a los lectores entender el apócrifo como un texto válido y coherente, pero no canónico. 


\section{Bibliografía}

Assouline, P. Hergé. París, Gallimard, 1996.

Battaglia, S. Grande Dizionario della Lingua Italiana. Vol. 12. Turín, Unione Tipografica-Editrice, 1984.

Brunot, F. Histoire de la Langue Française des Origines à Nos Jours. Vol vi: le XVIIIe siecle. París, Librairie Armand Colin, 1996.

Castillo, F. Tintín-Hergé. Una vida del siglo xx. Madrid, Fórcola Ediciones, 2019.

Derecho, A. «Archontic Literature.A Definition, a History, and Several Theories of Fan Fiction», en Hellekson, K. y Busse, K. (eds.) Fan Fiction and Fan Communities in the Age of the Internet. Jefferson, McFarland \& Company Inc., 2006, pp. 61-78.

Eco, U. Obra abierta. Barcelona, Editorial Ariel, 1990.

Genette, G. Palimpsestos. La literatura de segundo grado. Madrid, Taurus, 1989.

Hergé. El loto azul. Barcelona, Editorial Juventud, 2009 [1936].

—Tintín en el Tíbet. Editorial Juventud, 2017 [1960].

—Tintín y el Arte-Alfa. Barcelona, Editorial Juventud, 2016 [1987].

—Tintin y los Pícaros. Barcelona, Editorial Juventud, 2000 [1976].

Hoesterey, I. Pastiche. Cultural memmory, in art, fllm, literature. Bloomington, Indiana University Press, 2001.

Letissier, G. Rewriting/reprising plural intertextualities. Newcastle, Cambridge Scholars, 2009.

Pérez-Gómez, M. A. «Analizando Neurope: la construcción de mundo en la obra de Miguel Ángel Martín», en CuCo, Cuadernos de cómic n.o 6 (2016), pp. 34-60. Disponible en: http://cuadernosdecomic.com/docs/revista6/Analizando\%20Neurope $\% 201 \mathrm{a} \% 20$ construccion $\% 20 \mathrm{de} \% 20$ mundo $\% 20$ en $\% 201 \mathrm{a} \% 20$ obra $\% 20 \mathrm{de} \% 20$ miguel\%20angel\%20martin.pdf 
Pugh, S. The Democratic Genre. Fan Fiction in a Literary Context. Bridgend, Poetry Wales Press Ltd, 2005.

Rodier, Y. «Tintín». En Yves Rodier Illustrateur. Disponible en: https://web.archive.org/web/20021205023140/http://www.geocities.com/yves rodier/tintin.html

—Le lac de la sorciere. Éditions Hommage, 2003.

-Tintin et l'Art-Alph. Les Arumbayas, 1991.

-Tintin et l'Art-Alph. Une aventure de Tintin reporterpigiste au XXe siècle. ¿1995?

-Un jour dans un aeroport. Rascarman, 1996.

Sadoul, N. Tintin et moi, Entretiens avec Hergé. París, Casterman, 1983.

Sánchez-Biosca, V. Una cultura de la fragmentación. Pastiche, relato y cuerpo en el cine y la televisión. Valencia, Filmoteca de la Generalitat Valenciana, 1995.

Wolf, M. J. P. Building imaginary worlds : the theory and history of subcreation. New York, Routledge, 2013. 